\title{
Intrathecal clonidine as adjuvant for labor analgesia, spinal anesthesia, and postoperative analgesia in caesarean section
}

\begin{abstract}
Spinal adjuvants drugs are use to enhance analgesia and anesthesia in several clinical scenarios. Clonidine has been used in anesthesia since 1982 to reduce needs of anesthetics, to provide cardiovascular stability, for anxiolysis, for sedation, and to treat pain. Although its spinal use in obstetrics patients still controversial, there is sufficient information to consider spinal clonidine as a safe adjuvant to enhance spinal labour analgesia and to improve spinal anesthesia for caesarean section, and also to augment spinal postoperative anesthesia after surgical delivery. Using recommended doses, the usual side effects of subarachnoid clonidine are moderate hypotension, non harm fetal arrhythmias, and moderate mother sedation.
\end{abstract}

Keywords: Spinal clonidine, Labour analgesia, Caesarean section
Volume I Issue I - 2014

Victor MWhizar Lugo

Department of Anaesthesiology, Northwest Medical Center, Mexico

Correspondence: Victor MWhizar Lugo, Internal Medicine, Intensive Care, Anaesthesiology, Northwest Medical Center, Mission San Diego 2993-306, Zona Urbana Rio Tijuana, Tijuana BC, Mexico CP 22320, Mexico, Tel +52-664-684-8905, Fax +52 664-684-8906,Email vwhizar@anestesia-dolor.org

Received: May 23, 2014 | Published: May 28, 2014

\section{Introduction}

The role of anesthesiologist in obstetric practice has many duties such labour analgesia, anesthesia for vaginal delivery, for caesarean section, for abortion, for non-obstetric surgeries during pregnancy, postoperative analgesia, and at times assist in the resuscitation of the newborn. Neuraxial analgesia is a popular technique to manage labor pain and has being considered as the gold standard in obtaining maternal pain relief during labor. It can be done in three different ways: epidural, spinal and combining epidural-spinal. Each one has its advantages and side effects on the mother and/or the fetus-newborn. ${ }^{1-3}$ Increase in the incidence of fetal heart rate changes after intrathecal analgesia has been reported, though fetal bradycardia caused by labor analgesia-anesthesia does not usually increase the risk of emergent operative deliveries.

Nowadays spinal anesthesia is the technique of choice for caesarean section. It is safe, effective, easy to perform and inexpensive. Its main limitations are its short duration of action and do not provide prolonged postoperative analgesia when it is performed only with local anesthetics. ${ }^{4-6}$ Adding adjuvant drugs to intrathecal local anesthetics improves quality and duration of spinal blockade, and prolongs postoperative analgesia. It is also possible to reduce dose of local anesthetics, as well as total amount of systemic postoperative analgesics. Spinal clonidine has been used for labor analgesia, to enhance spinal anesthesia during caesarean section, and for postoperative pain relief. Its use tends to be more frequent in this field, since it reduces opioids doses, and thus the side effects such as emesis and maternal pruritus, and the possibility of late respiratory depression secondary to rostral opioid distribution. Theoretically, it could also reduce the fetal bradycardia. ${ }^{7-12}$ This mini-review is an up to date of the pros and cons of the use of spinal clonidine in obstetric patients.

\section{Clonidine}

This alpha 2 adrenergic receptor agonist was developed in 1962 as an effort to make a nasal decongestant. It was marketed as antihypertensive in 1972 since its effect to decrease sympathetic outflow from CNS and to diminish pre-synaptic nor-epinephrine release. ${ }^{13}$ It is an imidazoline derivative that exists as a mesomeric compound, with a molecular weight of 266.56 , chemical name is Benzenamine,2,6dichloro-N-2-imidazolindinylidene mono-hydrochloride and 2-((2,6-dichlorophenyl)imino)imidazolidine mono-hydrochloride. 1 shows its structural formula $\left(\mathrm{C}_{9} \mathrm{H}_{9} \mathrm{C}_{12} \mathrm{~N}_{3} \cdot \mathrm{HCl}\right)$. Clonidine stimulates alpha2 adrenoreceptors in the brain and spinal cord, resulting in reduction of sympathetic outflow from the central nervous system and in decreased in peripheral resistance, renal vascular resistance, plasma renin activity, heart rate, cardiac output, and blood pressure. Normal postural reflexes are intact; therefore, orthostatic symptoms are mild and infrequent. Plasmatic level of clonidine peaks in approximately 3 to 5 hours and the plasma half-life ranges from 12 to 16 hours. The half-life increases up to 41 hours in patients with severe impairment of renal function. Following oral administration, approximately $75 \%$ is bioavailable in men, about $40-60 \%$ of the absorbed dose recovered unchanged in the urine in 24 hours. About $50 \%$ of the absorbed dose is metabolized in the liver. Severe adverse side effects are infrequent, and well tolerated in most patients. Sedation and dry mouth are the most common side effects, are usually related to dose and duration of administration. $^{14,15}$

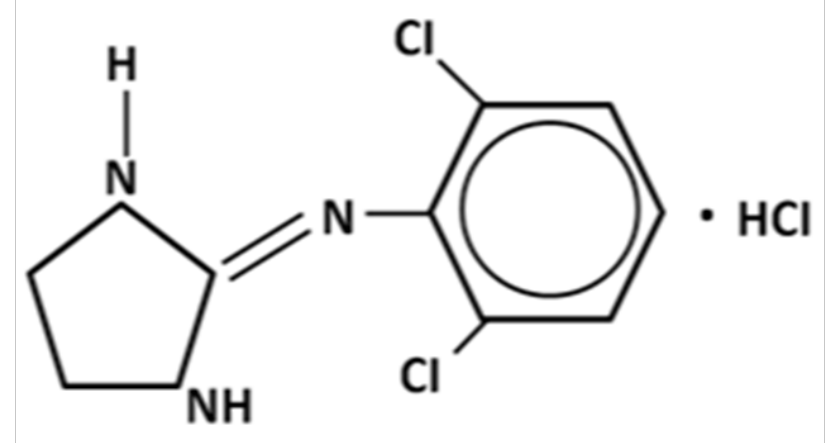

Figure I Clonidine.

\section{Adjuvant for spinal labor analgesia}

Labor pain encounter is affected by physiological and psychosocial factors and usually is so intense that most women require pain relief. Nowadays analgesia for labor delivery is safer than ever. An ideal 
labor analgesia plan needs to embrace newer procedures and adjuvant drugs in order to facilitate ambulation, excellent pain relief, patient comfort and no deleterious side effects to either the parturient or the fetus-neonate. It can be done using non-pharmacological measures and/or employing pharmacological products. ${ }^{1,16,17}$ At the present time the advances in pharmacology of labor analgesia converge on the mechanisms to target spinal pain receptors, and the efficacy and safety of old and new drugs and techniques; i.v. remifentanyl for patient controlled analgesia, low dose of diluted local anesthetics, and addition of neuraxial adjuvants like opioids, neostigmine, and clonidine. ${ }^{18-24}$

A single spinal injection of local anaesthetics is not universally recommended for labour analgesia due to its short time of duration. In order to overcome this limitation, several drugs have been used as adjuvants to local anesthetics. Opioids are the most used drugs, combined with small doses of bupivacaine, ropivacaine or levobupivacaine. Alpha2 adrenergic agonists, clonidine and dexmedetomidine, have been investigated to enhance quality and duration of spinal local anesthetics in many clinical scenarios, including obstetrics patients, with a diversity of results.

\section{Spinal clonidine for labor analgesia}

In 1989, Eisenach and coworkers demonstrated that epidural clonidine did not affect sheep fetus; ${ }^{9}$ they studied the acute maternal and fetal effects of $300 \mu \mathrm{g}$ epidural clonidine in near term ewes, and found that epidural clonidine augmented maternal and fetal serum glucose by $30 \%$ one hour after injection, without changes in cortisol and arterial blood gas tension. There were minor decreases (10-15\%) in heart rate in ewe and fetus, without altering maternal and fetal blood pressure, intra-uterine pressure, or uterine blood flow. Maternal and fetal serum clonidine concentrations peaked at $58 \pm 8$ and $73 \pm 5 \mathrm{~min}$ following peridural injection, respectively, and declined with similar half-lives. Heart rate correlated negatively with serum clonidine concentration in both ewe and fetus $(\mathrm{p}<.05)$. Since this initial research, many clinical studies have been done using neuroaxial clonidine mixed with local anesthetics and/or opioids. A year later, these same researchers studied the effects of high doses of intrathecal clonidine in sheep ${ }^{25}$ and found that clonidine altered maternal blood pressure in a biphasic mode (hypotension with lower dose and return to baseline values with higher dose, it also produced a dose dependent decrease in fetal and maternal heart rate. They mentioned that fetal bradycardia may limit the efficacy of spinal clonidine if used more than $10 \mu \mathrm{g} / \mathrm{kg}$ in obstetrics.

Most studied doses of intrathecal clonidine for labor analgesia range from 15 to $45 \mu \mathrm{g}$ mixed with opioids and/or local anesthetics. The first clinical report on intrathecal clonidine for labour analgesia is an abstract published by Chiari et al., ${ }^{16}$ using $100 \mu \mathrm{g}$ alone or combined with sufentanil $2 \mu \mathrm{g}$ versus sufentanil alone. Clonidine analgesia was superior and longer than sufentanil, and the mixture of both drugs produced more profound and lasting analgesia but more hypotension. In a preliminary open-label study done by Mercier et al. ${ }^{6}$ comparing sufentanil $5 \mu \mathrm{g}+$ clonidine $30 \mu \mathrm{g}$ versus sufentanil $5 \mu \mathrm{g}$ alone injected intrathecally to alleviate pain during the first stage of labor, the authors demonstrated that clonidine potentiate labor analgesia and side effects such hypotension, maternal pruritus and sedation were similar in both groups. In a second research of the same group ${ }^{10}$ they studied 53 nulliparous women in painful labour using the same doses, but followed by $5 \mathrm{mg}$ of epidural bupivacaine. In this study the duration of analgesia was longer in the sufentanil-clonidine group versus sufentanil alone ( $125 \pm 46$ versus $97 \pm 30 \mathrm{~min}, \mathrm{p}=0.007$ ).
There were more incidents of hypotension and ephedrine needs in those patients who received sufentanil and clonidine. The incidence of fetal heart rate abnormalities during the first $30 \mathrm{~min}$ after spinal injection was similar in both groups (17\% versus $19 \%)$. No parturient had motor blockade. Gautier et al. ${ }^{7}$ found that $30 \mu \mathrm{g}$ of intrathecal clonidine plus 2.5 or $5 \mu \mathrm{g}$ intrathecal sufentanil increased the duration of labor analgesia during the first stage without undesirable maternal or fetal effects. In a 30 randomized patients, ${ }^{26}$ comparing subarachnoid clonidine $50 \mu \mathrm{g}$, plus sufentanil $7.5 \mu \mathrm{g}$ and bupivacaine $2.5 \mathrm{mg}$ versus a mixture of sufentanil-bupivacaine without clonidine in first stage labour pain, the researchers were able to demonstrated significantly prolonged analgesia in those women treated whit clonidine $(197 \pm 70$ versus $132 \pm 39 \mathrm{~min} ; \mathrm{p}=0.004)$. Motor block, sedation and hypotension were not critical and similar in all patients. $\mathrm{Sia}^{27}$ compared 15 and $30 \mu \mathrm{g}$ clonidine with a control group with no clonidine. All randomized parturient were spinally injected with sufentanil $5 \mu \mathrm{g}$ and bupivacaine $1.25 \mathrm{mg}$ to induce labor analgesia in 48 patients. Clonidine 15 and $30 \mu \mathrm{g}$ produced an extended duration of analgesia compared with sufentanil-bupivacaine alone $(144 \pm 27.9,165 \pm 31.8$ versus $111 \pm 21.9$ min, respectively, $\mathrm{p}<0.01$ ). In addition, both doses of clonidine induced a more rapid onset and higher quality of analgesia. A higher cephalad sensory block was detected with the higher clonidine dose (median T3 versus T4, $\mathrm{p}<0.05$ ). Sedation and hypotension were more commonly with $30 \mu \mathrm{g}$ than in either no clonidine or clonidine $15 \mu \mathrm{g}$ ( 9 versus 2.5 and 9 versus 1.3 , respectively, $\mathrm{p}<0.05$ ). In Indonesia, ${ }^{8}$ a study including 62 laboring women (45 primigravidas and 17 multigravidas) mixing spinal bupivacaine $2.5 \mathrm{mg}$ morphine $250 \mu \mathrm{g}$ and clonidine $45 \mu \mathrm{g}$ found excellent analgesia with maternal satisfaction in $92 \%$. Significantly, 49 patients $(79 \%)$ stated that they would select the same technique for future labor pain. Labbene et al. ${ }^{11}$ added clonidine $15 \mu \mathrm{g}$ to 2.5 $\mathrm{mg}$ isobaric bupivacaine and $5 \mu \mathrm{g}$ sufentanil during combined spinalepidural analgesia resulting in extended duration of analgesia without increasing side effects.

Chiari et al. ${ }^{28}$ did the first study using spinal clonidine as a sole drug for labor analgesia; in 36 parturient with $<6 \mathrm{~cm}$ cervical dilation; they compared 50,100 , and $200 \mu \mathrm{g}$ intrathecal clonidine and found that labour pain was significantly reduced in all patients, analgesia duration was significantly longer with $200 \mu$ g (median 143; range 75-210 $\mathrm{min}$ ), with $100 \mu \mathrm{g}$ (median 118; range 60-180 $\mathrm{min}$ ) and using $50 \mu \mathrm{g}$ (median 45; range 25-150 $\mathrm{min}$ ). Hypotension was associated with $200 \mu \mathrm{g}$ and the need of i.v. ephedrine more often than in the other groups.

There are controversies in the use of spinal clonidine for labour analgesia as some researchers have found a higher frequency of maternal hypotension, foetal arrhythmia, and worse neonatal umbilical artery $\mathrm{pH}$. Therefore, some of them do not recommend its use. ${ }^{29-31}$ The study done by Paech et al. ${ }^{32}$ with subarachnoid fentanyl $20 \mu \mathrm{g}+$ bupivacaine $2.5 \mathrm{mg}$, plus either saline or clonidine 15,30 or $45 \mu \mathrm{g}$ found that addition of clonidine to fentanyl-bupivacaine reduced maternal blood pressure and did not significantly augment the duration of spinal labour analgesia. Two Brazilian studies ${ }^{33,34}$ found that $30 \mu \mathrm{g}$ clonidine added to hypobaric or hyperbaric bupivacaine and sufentanil did not prolonged analgesia duration. There was a higher incidence of hypotension in patients receiving isobaric bupivacaine. To avoid hypotension due to the combination of spinal clonidineopioids-diluted local anesthetics, epidural clonidine can be used in doses of $75 \mu \mathrm{g} .{ }^{35}$

Fetal heart rate abnormalities are not exclusive of spinal clonidine, have also been described with opioids such sufentanil. ${ }^{36,37}$ Usually fetal heart rate changes do not affect neonatal outcome in healthy 
population. When low doses of clonidine with or without opioids are used for spinal labor analgesia, we must remember that at the end of pregnancy there is a degree of auto analgesia mediated by endorphins. ${ }^{38}$ Even though neuraxial analgesia is the most efficient and safest mode of labor analgesia, ${ }^{1-3,39}$ the use of spinal clonidine mixed with opioids and/or local anesthetics must be must be used cautiously to avoid hypotension. The optimal dose of subarachnoid clonidine to augment labor analgesia obtained with the spinal mixture of opioids-local anaesthetic range from 15 to $30 \mu \mathrm{g}$ larger doses would induce more deleterious side effects.

\section{Spinal clonidine for cesarean section}

Although some controversies, nowadays spinal anesthesia is the most used technique for cesarean section. ${ }^{40-42}$ Currently, opioids are the drugs most commonly used as adjuvants in this clinical scenario, but its side effects are troubling. Low doses of spinal clonidine in cesarean section are used to improve the anaesthetic block, to reduce the dose of local anesthetics, and to prolong postoperative analgesia. It can also be combined with intrathecal opioids, as there is a synergic effect.

A double blind study ${ }^{43}$ carried out to evaluate the analgesic effect of clonidine in patients undergoing elective cesarean section, doses of $150 \mu \mathrm{g}$ were injected $45 \mathrm{~min}$ after general anesthesia and compared to intrathecal saline as control group. Pain intensity was lower in clonidine treated patients from 20 to $120 \mathrm{~min}$ after intrathecal injection $(p<0.05)$, request for first analgesic was also longer in the clonidine group $414 \pm 128 \mathrm{~min}$ versus $181 \pm 169 \min (\mathrm{p}<0.01)$. Clonidine side effects were severe; hypotension with a maximal reduction of systolic $(15 \pm 9 \%)$, diastolic $(22 \pm 12 \%)$ and mean arterial pressure $(18 \pm 12 \%)$. Sedation was significantly more intense compared to saline $(\mathrm{p}<0.05)$; also dried mouth was more commonly $(\mathrm{p}<0.01)$. Although these data suggest that $150 \mu \mathrm{g}$ subarachnoid clonidine is effective to treat acute pain after cesarean section, it has side effects such as hypotension, sedation, and dryness of mouth. Filos et al. ${ }^{44}$ using 150, 350 and $450 \mu \mathrm{g}$ of spinal clonidine performed to evaluate the dose-response hemodynamic and analgesic profiles in the immediate postoperative period of caesarean section under general anesthesia. The authors found that pain was less in all groups in a dose dependent mode: request for first analgesic $402 \pm 75 \mathrm{~min}, 570 \pm 76 \mathrm{~min}$, and $864 \pm 80$ min respectively $(\mathrm{p}<0.01-0.001)$. Clonidine reduced mean arterial pressure compared with baseline only in those patients treated with $150 \mu \mathrm{g}(21 \pm 13 \%, \mathrm{p}<0.05)$. Sedation was evident in all groups. Respiratory rate and motor activity of the lower extremities were unaffected in all three groups. The hemodynamic stability after 300 and $450 \mu \mathrm{g}$ suggested a pressor consequence at peripheral sites. Other studies have found that $75 \mu \mathrm{g}$ is a safe dose; prolong the anesthetic block and enhance postoperative analgesia, with minimal side effects and no harm to the newborn. ${ }^{45-47}$ In a randomized, double blind, dose finding study, Peach et al. ${ }^{48}$ compared intrathecal clonidine mixed with fentanyl and morphine versus clonidine plus morphine in 240 women undergoing cesarean section with hyperbaric $0.5 \%$ bupivacaine. A dose-finding analysis showed similar postoperative efficacy and side effects for groups receiving morphine $100 \mu \mathrm{g}$ with clonidine 60,90 , or $150 \mu \mathrm{g}$ and concluded that a multimodal approach to postcesarean analgesia, using subarachnoid bupivacaine, fentanyl, morphine $100 \mu \mathrm{g}$, and clonidine $60 \mu \mathrm{g}$, improves pain relief compared with morphine $100 \mu \mathrm{g}$ or clonidine $150 \mu \mathrm{g}$ alone, but increases intraoperative sedation and may increase perioperative vomiting. In another dose finding study ${ }^{49}$ comparing $15 \mu \mathrm{g}, 30 \mu \mathrm{g}$ and $60 \mu \mathrm{g}$ of clonidine added to hyperbaric bupivacaine $0.5 \%$ the authors found a dose dependent variability of analgesia duration and sedation. Duration of analgesia was significantly higher in those patients who received clonidine $60 \mu \mathrm{g}$ as compared to the other two groups $(598.7 \pm 140.47$ versus $436.65 \pm 149.84$ and $387.1 \pm 97.05 \mathrm{~min}$ respectively). Sedation was also more in the highest dose. In this study the authors recommended $15 \mu \mathrm{g}$ and $30 \mu \mathrm{g}$ doses due to good postoperative analgesia and less sedation. In a recent study done by Khezri et al., ${ }^{46}$ the authors compared three groups: clonidine $75 \mu \mathrm{g}$ plus bupivacaine $10 \mathrm{mg}$, fentanyl $25 \mu \mathrm{g}$ plus bupivacaine $10 \mathrm{mg}$, and bupivacaine $10 \mathrm{mg}$ plus saline as control group. They found that spinal clonidine prolonged duration of anesthesia (275.10 \pm 96.09 versus $192.33 \pm 30.36$ versus $211.73 \pm 74.80$ respectively). Also, mean time for first analgesic request was longer in clonidine group; however the total analgesic consumption within the first postoperative day were similar to fentanyl treated group. In another study with clonidine $75 \mu \mathrm{g}$ plus hyperbaric bupivacaine prolongs spinal anesthesia and improves early postoperative analgesia after caesarean section, but does not diminish morphine needs during the first 24 hours of the postoperative period.$^{50}$ In a recent study, $37.5 \mu \mathrm{g}$ of clonidine added to hyperbaric bupivacaine was suggested as the optimal dose for emergency cesarean surgery, allowing reduction of up to $18 \%$ of the total dose of hyperbaric bupivacaine. ${ }^{51}$ As a single drug, subarachnoid clonidine is not recommended for anesthesia neither for post caesarean analgesia.

\section{Conclusion}

Should we administer intrathecal clonidine in obstetric patients? This same question was asked in an editorial published in 2000; $\mathrm{D}^{\prime}$ Angelo ${ }^{52}$ comments the results of Paech et al..$^{53}$ on epidural clonidine for labor pain and recommends further studies before taking clonidine as part of our armamentarium in obstetric patients. Under the results of subsequent clinical investigations done by many authors in different countries, I think that intrathecal clonidine is a safe drug in obstetric patients when mentioned doses are observed. So, if the answer to that question is yes, what is the ideal dose for labor analgesia, for spinal anesthesia for caesarean section, or for postoperative analgesia? We still need more clinical studies to adequately respond to this question. Moreover, we have to keep in mind that the FDA maintains its recommendation not to use epidural clonidine in obstetrics. This organization does not mention the use of intrathecal clonidine in this clinical scenario.

\section{Acknowledgments}

None.

\section{Conflicts of Interset}

None.

\section{References}

1. Jones L, Othman M, Dowswell T, et al. Pain management for women in labour: an overview of systematic reviews. Cochrane Database Syst Rev. 2012;3:CD009234.

2. Okutomi T, Saito M, Mochizuki J, et al. A double-blind randomized controlled trial of patient-controlled epidural analgesia with or without a background infusion following initial spinal analgesia for labor pain. Int J Obstet Anesth. 2009;18(1):28-32.

3. Halpern SH, Carvalho B. Patient-controlled epidural analgesia for labor Anesth Analg. 2009;108(3):921-928.

4. Misirlioglu K, Sivrikaya G, Hanci A, et al. Intrathecal low-dose levobupivacaine and bupivacaine combined with fentanyl in a randomized controlled study for caesarean section: blockade characteristics, maternal and neonatal effects. Hippokratia. 2003;17(3):262-267. 
5. BirBach DJ, Browne IM. Anesthesia for Obstetrics. In: Miller RD (Ed.), Miller's Anesthesia. (7th edn) Churchill Livingston Elsevier, Australia, 2010; pp. 2203-2240.

6. Mercier FJ, Boulay G, Ben Ayed M, et al. Combined spinal and epidural analgesia for labor. Prolongation by addition of a minidose of clonidine to sufentanil. An initial study. Ann Fr Anesth Reanim. 1996;15(3):263-265.

7. Gautier PE, De Kock M, Fanard L, et al. Intrathecal clonidine combined with sufentanil for labor analgesia. Anesthesiology. 1998;88(3):651-656.

8. Kuczkowski KM, Chandra S. Maternal satisfaction with single-dose spinal analgesia for labor pain in Indonesia: a landmark study. $J$ Anesth. 2008;22(1):55-58.

9. Eisenach JC, Castro MI, Dewan DM, et al. Epidural clonidine analgesia in obstetrics: sheep studies. Anesthesiology. 1989;70(1):51-56.

10. Mercier FJ, Dounas M, Bouaziz H, et al. The effect of adding a minidose of clonidine to intrathecal sufentanil for labor analgesia. Anesthesiology. 1998;89(3):594-601.

11. Labbene I, Gharsallah H, Abderrahman A, et al. Effects of $15 \mathrm{mcg}$ intrathecal clonidine added to bupivacaine and sufentanil for labor analgesia. Tunis Med. 2011;89(11):853-859.

12. Van de Velde M. Neuraxial analgesia and fetal bradycardia. Curr Opin Anaesthesiol. 2005;18(3):253-256.

13. Bloor BC. Clonidine and other alpha2 adrenergic agonists: An important new drugs class for the perioperative period. Sem Anesth. 1988;7:170-177.

14. Houston MC. Clonidine hydrochloride. South Med J. 1982;75(6):713-719.

15. Robinson ES, Nutt DJ, Hall L, et al. Autoradiographical and behaviora effects of a chronic infusion of antisense to the alpha2D-adrenoceptor in the rat. Br J Pharmacol. 1999;128(3):515-522.

16. Chiari A, Lorber C, Taslimi R, et al. Combination of low dose intrathecal sufentanil and clonidine for obstetric analgesia. Regional Anesthesia \& Pain Medicine. 1996;21(4):390-391.

17. Beilin Y. Advances in labor analgesia. Mt Sinai $J$ Med. 2002;69(1-2):38-44.

18. Hong RW. Less is more: the recent history of neuraxial labor analgesia. Am J Ther. 2010;17(5):492-497.

19. Roelants F. The use of neuraxial adjuvant drugs (neostigmine, clonidine) in obstetrics. Curr Opin Anaesthesiol. 2006;19(3):233-237.

20. Datta S. Spinal opiates in obstetrics. In Obstetric anaesthesia handbook. (4thedn), Springer New York, USA, 2006; pp. 89-99.

21. Goudra BG, Singh PM. Remifentanil in labor. J Obstet Anaesth Crit Care. 2013;3(2):74-76.

22. Sultan P, Murphy C, Halpern S, et al. The effect of low concentrations versus high concentrations of local anesthetics for labour analgesia on obstetric and anesthetic outcomes: a meta-analysis. Can J Anaesth. 2013;60(9):840-854.

23. Pandya ST. Labour analgesia: Recent advances. Indian J Anaesth 2010;54(5):400-408.

24. Fernandez-Guisasola J, Garcia del Valleb S, Gomez-Arnauc JI. Tecnica combinada subaracnoidea-epidural para la analgesia obstetrica. Rev Esp Anestesiol Reanim. 2000;47:207-215.

25. Eisenach JC, Dewan DM. Intrathecal clonidine in obstetrics: sheep studies. Anesthesiology. 1990;72(4):663-668.

26. D'Angelo R, Evans E, Dean LA, et al. Spinal clonidine prolongs labor analgesia from spinal sufentanil and bupivacaine. Anesth Analg. 1999;88(3):573-576.
27. Sia AT. Optimal dose of intrathecal clonidine added to sufentanil plus bupivacaine for labour analgesia. Can J Anaesth. 2000;47(9):875-880.

28. Chiari A, Lorber C, Eisenach JC, et al. Analgesic and hemodynamic effects of intrathecal clonidine as the sole analgesic agent during first stage of labor: a dose-response study. Anesthesiology. 1999;91(2):388-396.

29. Missant C, Teunkens A, Vandermeersch E, et al. Intrathecal clonidine prolongs labour analgesia but worsens fetal outcome: a pilot study. Can J Anaesth. 2004;51(7):696-701.

30. Dewandre PY. The right drug and dose for neuraxial labour analgesia. Acta Anaesthesiol Belg. 2006;57(4):395-399.

31. Belhadj Amor M, Draief A, Ouezini R, et al. 30 microg intrathecal clonidine prolongs labour analgesia, but increases the incidence of hypotension and abnormal foetal heart rate patterns. Ann Fr Anesth Reanim. 2007;26(11):916-920

32. Paech MJ, Banks SL, Gurrin LC, et al. A randomized, double-blinded trial of subarachnoid bupivacaine and fentanyl, with or without clonidine, for combined spinal/epidural analgesia during labor. Anesth Analg. 2002;95(5):1396-1401.

33. Cardoso MM, Papa FV, Vieira RF, et al. The effect of adding subarachnoid clonidine to hyperbaric bupivacaine and sufentanil during labor analgesia. Rev Bras Anestesiol. 2006;56(2):119-125.

34. Tebaldi TC, Malbouisson LM, Kondo MM, et al. Effects of the addition of subarachnoid clonidine to the anesthetic solution of sufentanil and hyperbaric or hypobaric bupivacaine for labor analgesia. Rev Bras Anestesiol. 2008;58(6):593-601.

35. Van de Velde M, Berends N, Kumar A, et al. Effects of epidural clonidine and neostigmine following intrathecal labour analgesia: a randomised, double-blind, placebo-controlled trial. Int J Obstet Anesth. 2009;18(3):207-214.

36. Van de Velde M, Teunkens A, Hanssens M, et al. Intrathecal sufentanil and fetal heart rate abnormalities: a double-blind, double placebo-controlled trial comparing two forms of combined spinal epidural analgesia with epidural analgesia in labor. Anesth Analg. 2004;98(4):1153-1159.

37. Patel NP, El-Wahab N, Fernando R, et al. Fetal effects of combined spinal-epidural vs epidural labour analgesia: a prospective, randomised double-blind study. Anaesthesia. 2014;69(5):458-467.

38. Eisenach JC, Dobson CE, Inturissi CE, et al. Effect of pregnancy and pain on cerebrospinal fluid immunoreactive enkephalins and norepinephrine in healthy humans. Pain. 1990;43(2):149-154.

39. Potdar MP, Kamat LL, Jha T. Intrathecal isobaric ropivacaine-fentanyl versus intrathecal isobaric bupivacaine-fentanyl for labor analgesia: A controlled comparative double-blinded study. J Obstet Anaesth Crit Care. 2014;4(1):12-17.

40. Arzola C, Wieczorek PM. Efficacy of low-dose bupivacaine in spinal anaesthesia for Caesarean delivery: systematic review and metaanalysis. Br J Anaesth. 2011;107(3):308-318.

41. Qublan HS, Merhej A, Dabbas MA, et al. Spinal versus general anesthesia for elective cesarean delivery: a prospective comparative study. Clin Exp Obstet Gynecol. 2001;28(4):246-248.

42. Afolabi BB, Lesi FE. Regional versus general anaesthesia for caesarean section. Cochrane Database Syst Rev. 2012;10:CD004350.

43. Filos KS, Goudas LC, Patroni O, et al. Intrathecal clonidine as a sole analgesic for pain relief after cesarean section. Anesthesiology. 1992;77(2):267-274.

44. Filos KS, Goudas LC, Patroni O, et al. Hemodynamic and analgesic profile after intrathecal clonidine in humans. A dose-response study. Anesthesiology. 1994;81(3):591-601.

45. Bhure A, Kalita N, Ingley $P$, et al. Comparative study of intrathecal hyperbaric Bupivacaine with Clonidine, Fentanyl and Midazolam for quality of anaesthesia and duration of post operative pain relief in patients undergoing elective caesarean section. People's Journal of Scientific Research. 2012;5(1):19-23. 
46. Khezri MB, Rezaei M, Delkhosh Reihany M, et al. Comparison of postoperative analgesic effect of intrathecal clonidine and fentanyl added to bupivacaine in patients undergoing cesarean section: A prospective randomized double-blind study. Pain Res Treat. 2014;2014: 513628.

47. Singh R, Gupta D, Jain A. The effect of addition of intrathecal clonidine to hyperbaric bupivacaine on postoperative pain after lower segment caesarean section: A randomized control trial. Saudi J Anaesth 2013;7(3):283-290.

48. Paech MJ, Pavy TJ, Orlikowski CE, et al. Postcesarean analgesia with spinal morphine, clonidine, or their combination. Anesth Analg. 2004;98(5):1460-1466.

49. Shah BB, Joshi SS, Shidhaye RV, et al. Comparison of different doses of clonidine as an adjuvant to intrathecal bupivacaine for spinal anesthesia and postoperative analgesia in patients undergoing caesarian section. Anaesth Pain \& Intensive Care. 2012;16(3):266-272.
50. van Tuijl I, van Klei WA, van der Werff DB, et al. The effect of addition of intrathecal clonidine to hyperbaric bupivacaine on postoperative pain and morphine requirements after Caesarean section: a randomized controlled trial. Br J Anaesth. 2006;97(3):365-370.

51. Bajwa SJ, Bajwa SK, Kaur J, et al. Prevention of hypotension and prolongation of postoperative analgesia in emergency cesarean sections: A randomized study with intrathecal clonidine. Int J Crit Illn Inj Sci. 2012;2(2):63-69.

52. D'Angelo R. Should we administer epidural or spinal clonidine during labor? Reg Anesth Pain Med. 2000;25(1):3-4.

53. Paech MJ, Pavy TJG, Orlikowski CEP, et al. Patient-controlled epidural analgesia in labor: The addition of clonidine to bupivacaine-fentanyl. Reg Anesth Pain Med. 2000;25(1):34-30. 